\title{
High level of circulating vitamin D during neoadjuvant therapy may lower risk of metastatic progression in high-risk rectal cancer
}

\author{
Hanna Abrahamsson 1,2, Alina C. Porojnicu ${ }^{1,3}$, Jonas C. Lindstrøm ${ }^{4,2}$, Svein Dueland ${ }^{5}$, Kjersti Flatmark ${ }^{6,7,2}$, \\ Knut H. Hole ${ }^{8}$, Therese Seierstad ${ }^{8}$, Johan Moan ${ }^{9,10}$, Kathrine Røe Redalen ${ }^{1,11}$, Sebastian Meltzer ${ }^{1,2}$ and \\ Anne Hansen Ree ${ }^{1,2^{*}}$ (i)
}

\begin{abstract}
Background: Following curative-intent neoadjuvant therapy in locally advanced rectal cancer, metastatic progression is still dominant. We investigated if patients' circulating 25-hydroxyvitamin D [25(OH)D] levels were associated with outcome.

Methods: Serum 25(OH)D concentration was assessed by liquid chromatography-mass spectrometry in samples collected from 84 patients at baseline, completion of the neoadjuvant therapy, and treatment evaluation before surgery, and analyzed with respect to season, disease presentation, and treatment effects.

Results: In the cohort of patients residing at latitude $58-62^{\circ} \mathrm{N}$, baseline $25(\mathrm{OH}) \mathrm{D}$ differed significantly over the seasons, with highest measures (mean of $71.2 \pm 5.6 \mathrm{nmol} / \mathrm{L}$ ) in summer and lowest $(48.7 \pm 4.5 \mathrm{nmol} / \mathrm{L}$ ) in spring, and changed over the three-month neoadjuvant period till response evaluation solely owing to season. The patient subgroup with slightly reduced performance status, anemia, and T4 disease that did not respond to the neoadjuvant therapy (ypT4 cases), had significantly lower baseline $25(\mathrm{OH}) \mathrm{D}$ (below $50 \mathrm{nmol} / \mathrm{L}$ ) than $\mathrm{T} 4$ cases with response (ypT0-3) and T2-3 cases (above $60 \mathrm{nmol} / \mathrm{L}$ ). Compared to the $T 4$ patients with levels above $50 \mathrm{nmol} / \mathrm{L}$, regarded as sufficient for a healthy bone status, those presenting levels below had significantly heightened risk of disease progression (mainly metastasis) and death, with hazard ratio of 3 and 17, respectively, on adjustment for age, sex, body mass index, and season.
\end{abstract}

Conclusion: Rectal cancer T4 cases had high risk of metastatic progression and death if circulating 25(OH)D levels were insufficient but obtained short-term and long-term outcome to neoadjuvant treatment no worse than patients with T2-3 disease when 25(OH)D was sufficient.

Trial registration: ClinicalTrials.gov NCT00278694; registration date: 16 January 2006, retrospective to enrollment of the first 10 patients of the current report.

Keywords: Vitamin D, Rectal cancer, Neoadjuvant, Chemotherapy, Radiotherapy, Metastasis

\footnotetext{
* Correspondence: a.h.ree@medisin.uio.no

${ }^{1}$ Department of Oncology, Akershus University Hospital, P.O. Box 1000, 1478

Lørenskog, Norway

${ }^{2}$ Institute of Clinical Medicine, University of Oslo, Oslo, Norway

Full list of author information is available at the end of the article
}

(c) The Author(s). 2019 Open Access This article is distributed under the terms of the Creative Commons Attribution 4.0 International License (http://creativecommons.org/licenses/by/4.0/), which permits unrestricted use, distribution, and reproduction in any medium, provided you give appropriate credit to the original author(s) and the source, provide a link to the Creative Commons license, and indicate if changes were made. The Creative Commons Public Domain Dedication waiver (http://creativecommons.org/publicdomain/zero/1.0/) applies to the data made available in this article, unless otherwise stated. 


\section{Background}

With reference to the demography of colorectal cancer (CRC), principally owing to an aging population, the incidence in the Nordic countries is among the highest in the world [1]. It has been hypothesized that high incidence and poor prognosis may partly be attributed to an insufficient vitamin D status [2-4]. Circulating vitamin $\mathrm{D}$ is strongly associated with exposure to solar ultraviolet radiation [5], which in the Nordic countries (mainland latitude $55-72^{\circ} \mathrm{N}$ ) results in significant variation over the year $[6,7]$, especially if the diet is scarce in supplementary vitamin $\mathrm{D}$ in calendar months when the basic requirement cannot be met by sun exposure alone [8]. In both northern and southern regions of Norway the prognosis of CRC across all disease stages seems to be better when diagnosed in summer and fall compared to winter and spring $[9,10]$.

Exposure to sunlight causes conversion of 7dehydrocholesterol in the skin to cholecalciferol (vitamin $\mathrm{D}_{3}$ ), which is further metabolized by two-step hydroxylation via 25-hydroxycholecalciferol [25-hydroxyvitamin $\left.\mathrm{D}_{3}\left(25(\mathrm{OH}) \mathrm{D}_{3}\right)\right]$ to obtain the hormonally active form of vitamin $\mathrm{D}_{3}$, calcitriol (1,25-dihydroxyvitamin $\left.\mathrm{D}_{3}\right)$. This metabolite binds to the vitamin $\mathrm{D}$ receptor and turns it into an active transcription factor. In addition to its classic functions in the calcium homeostasis, a discrete number of target genes are implicated in biological processes that counteract malignant progression, such as cell cycle control, DNA damage repair, and apoptosis [11]. According to the Nordic Nutrition Recommendations, a serum level of 25(OH)D (endogenous and supplementary by diet) of $50 \mathrm{nmol} / \mathrm{L}$ is adequate to maintain healthy bone status [12], though it has been suggested that the optimum serum concentration for multiple health outcomes may be higher [13, 14]. Of note, vitamin $\mathrm{D}$ sufficiency may be protective against development of inflammatory bowel disease [15] and accordingly, deficient circulating levels are associated with heightened risk of CRC development in these patients [16], supporting an association between vitamin D, inflammation, and CRC.

Patients with locally advanced rectal cancer (LARC), typically presenting a primary tumor that grows either beyond the rectal wall ( $\mathrm{T} 3$ disease), into neighboring pelvic organs (T4 disease), or with local lymph node involvement, need to undergo neoadjuvant therapy before radical surgery is feasible. Histologic ypTN status of the surgical specimen is a surrogate marker for response to the neoadjuvant therapy in lieu of progression-free and overall survival (PFS, OS) as clinical endpoints. Patients with T4 disease are at particularly high risk of poor treatment outcome [17]. In a prospective LARC study [18], patients with mainly T3-4 and N-positive disease were given 4 weeks of induction chemotherapy and 5 weeks of sequential pelvic chemoradiotherapy before they proceeded to surgery approximately 7 weeks after completion of the neoadjuvant therapy (Fig. 1). ypTN status was determined and patients were followed to record recurrent disease and long-term survival.

To our knowledge, there are no previous reports on vitamin $\mathrm{D}$ status and outcome of combined-modality therapy in rectal cancer. In this post hoc analysis, we assessed circulating levels of $25(\mathrm{OH}) \mathrm{D}$, which in clinical practice are used as measure of the vitamin $\mathrm{D}$ status [19], at the time of diagnosis (termed baseline), at completion of the neoadjuvant therapy (termed post-Rx), and approximately 3 weeks before surgery (termed evaluation) in our study cohort (Fig. 1) and investigated if there were any associations with the season of diagnosis, disease presentation, and treatment effects.

\section{Methods}

\section{Patients and treatment}

Patient eligibility criteria of the LARC study (ClinicalTrials.gov NCT00278694) have been described previously [18]. Patients had to be Eastern Cooperative Oncology Group (ECOG) performance status 0 or 1. Ninety-seven patients were prospectively enrolled between 5 October 2005 and 3 March 2010 [18]. Within the current spin-off study, the 84 cases population excluded 10 patients with metastatic disease at presentation and three for whom serum $25(\mathrm{OH}) \mathrm{D}$ measurement failed. The neoadjuvant protocol has been detailed previously [18]. A preoperative evaluation of the neoadjuvant treatment was undertaken at a median of 31 (range, 2343) days after its completion, and surgery was done at a median of 21 (range, 7-41) days thereafter. In accordance with national guidelines at the time, patients did not proceed to further therapy.

\section{Serum sampling and analysis of $25(\mathrm{OH}) \mathrm{D}$}

Serum samples were collected at baseline $(n=84)$, immediately following completion of the neoadjuvant therapy (post-Rx; $n=63$ ), and at the time of evaluation ( $n=$ 60; Fig. 1). Analysis of vitamin D metabolites was undertaken at Haukeland University Hospital (Bergen, Norway) in January 2012 (i.e., after 19-75 months of sample storage at $\left.-80^{\circ} \mathrm{C}\right)$; serum and plasma $25(\mathrm{OH}) \mathrm{D}$ concentrations have shown to be largely unaffected by long-term storage $[20,21]$. The assay was based on liquid chromatography-mass spectrometry (Agilent Technology, Santa Clara, CA) implementing modifications of the originally described method [22]. The mean recovery of $25(\mathrm{OH}) \mathrm{D}$ was $77.2 \%$ [standard deviation (SD) 3.9\%] with intra-assay variation of $4.9 \%$ and detection limit at $<4 \mathrm{nmol} / \mathrm{L}$. Ergocalciferol (vitamin $\mathrm{D}_{2}$ ) can be prescribed as general vitamin $\mathrm{D}$ supplementation, and nine patients presented measurable values of its hydroxylated 


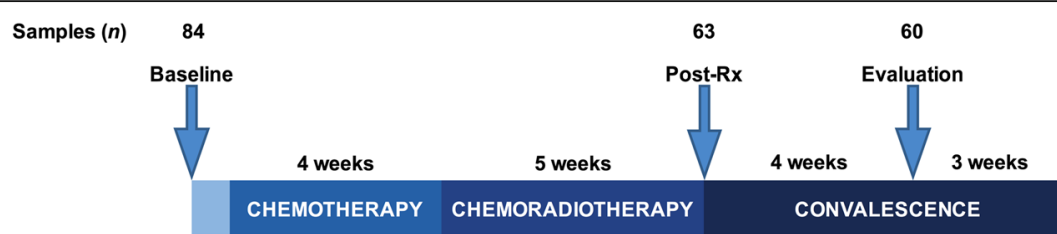

SURGERY

Fig. 1 The timing of serum sampling (arrows) within the neoadjuvant treatment protocol. Abbreviations: $n$ the numbers of samples at each sampling point, Post-Rx completion of neoadjuvant therapy

metabolite $25(\mathrm{OH}) \mathrm{D}_{2}$, which is considered equipotent with $25(\mathrm{OH}) \mathrm{D}_{3}$. Hence, for each of the study patients, the sum of serum levels of $25(\mathrm{OH}) \mathrm{D}_{3}$ and $25(\mathrm{OH}) \mathrm{D}_{2}$, for practical reasons designated $25(\mathrm{OH}) \mathrm{D}$, was used for analysis.

\section{Seasonal categorization}

Patients' places of residence were in southern Norway at latitude $58-62^{\circ} \mathrm{N}$ with a significant variation of solar ultraviolet radiation from one to the next of four seasons [7]. Cases were therefore categorized in four season groups: winter (1 December through 28/29 February), spring (1 March through 31 May), summer (1 June through 31 August), and fall (1 September through 30 November). The patients represented a standard Scandinavian population, the majority of which was Caucasian in the actual time period, but no registration of ethnicity or recording of vitamin D supplementation was undertaken within the study.

\section{Tumor volumetry}

For each patient, on the diagnostic magnetic resonance imaging, the tumor boundary was manually contoured by the study radiologist, and the tumor volume was calculated as previously described [23, 24].

\section{Treatment outcome measures}

The resected tumor specimens were prepared in accordance with the requirements of a validated protocol [25] and histologically evaluated for treatment response according to standard staging (ypTN). Regarding PFS and OS, data were censored on 8 August 2013, at which time $68 \%$ of patients had follow-up time of 5 years or longer.

\section{Statistical analyses}

All 25(OH)D measures had normal distribution and seasonal variation was tested with general linear models. The possible influence of factors other than season on the observed change in $25(\mathrm{OH}) \mathrm{D}$ measure during the neoadjuvant period for an individual patient was examined by a mixed-effect model with periodic cubic splines according to the visually explored development of $25(\mathrm{OH}) \mathrm{D}$ over time, with random intercepts for patients and fixed effects for treatment period. Demographic and clinical characteristics were expressed as median and range, mean $\pm S D$, or percentages in descriptive analyses and as mean \pm standard error (SE) in estimate analyses. Baseline tumor and lymph node stages and stages of histologic treatment response in the surgical specimens were dichotomized according to prognostic value. Continuous data with skewed distribution were logtransformed. PFS was calculated from the time of study enrollment to the day of recurrent disease (diagnosis of local recurrence or distant metastasis), death of any cause, or end of follow-up (a maximum of 5 years after the date of surgery or at final censoring), whichever occurred first. OS was measured from the date of enrollment to death of any cause or final censoring. Univariable association analyses were described by the results of independent-samples $t$-test, one-way analysis of variance, and Pearson correlation test, as appropriate, and adjusted for season by linear and logistic regression models. Associations between $25(\mathrm{OH}) \mathrm{D}$ levels and PFS or OS were analyzed with Cox proportional hazards models, and results were expressed as hazard ratio (HR) with 95\% confidence interval (CI). Age, sex, body mass index (BMI), and the season of serum sampling, which might influence the $25(\mathrm{OH}) \mathrm{D}$ level or disease outcome, were adjusted for in the multivariable models. Winter/ spring and summer/fall were used as collapsed categories in order to avoid violation of the models by small sample sizes. All statistical analyses were two-sided, and $p$-values less than 0.050 were generally used. Following Bonferroni correction for multiple testing of $25(\mathrm{OH}) \mathrm{D}$ and circulating markers possibly related to tumor immune responses (12 analyses), the $p$-value for significance was set to 0.0042 ( 0.050 divided by 12$)$. The mixed effect-model was performed in $\mathrm{R}$ using the lme4 and pbs packages [26]. All other analyses were carried out using STATA version 15 (StataCorp LCC, College Station, TX).

\section{Results}

Seasonal variation in serum $25(\mathrm{OH}) \mathrm{D}$ level

Figure 2 illustrates baseline serum $25(\mathrm{OH}) \mathrm{D}$ in the individual patients at the given time of diagnosis. Levels (mean of $59.1 \pm 22.7 \mathrm{nmol} / \mathrm{L}$ within the range of $15.3-$ $133.7 \mathrm{nmol} / \mathrm{L}$ for the entire population; $n=84$ ) were 


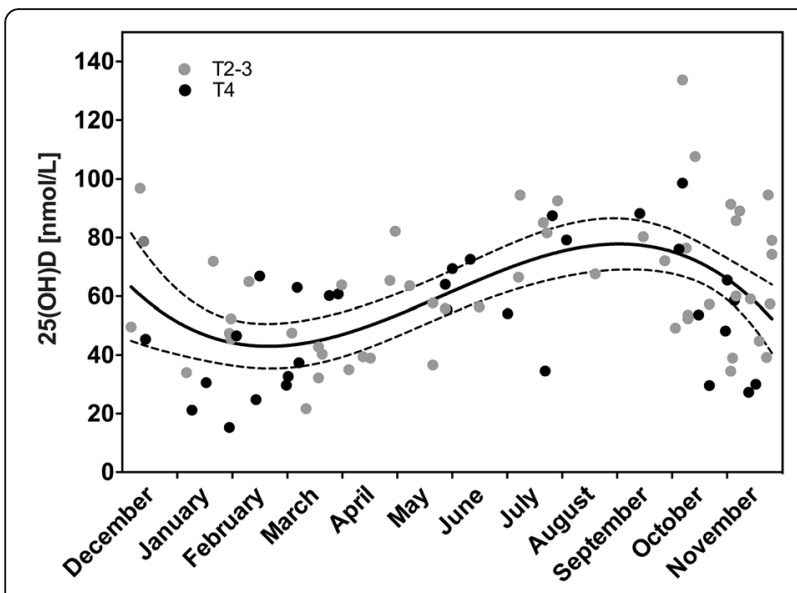

Fig. 2 Baseline serum level of 25-hydroxyvitamin D [25(OH)D], the time of the year of study enrollment, and tumor ( $T$ ) stage for each patient. The fit standard curve (solid line) with 95\% confidence bands (dashed lines) for the entire study population is shown

significantly different among the four season categories $(p=0.0017)$; mean was $49.5 \pm 5.3 \mathrm{nmol} / \mathrm{L}$ in winter $(n=$ 16), $48.7 \pm 4.5 \mathrm{nmol} / \mathrm{L}$ in spring $(n=22), 71.2 \pm 5.6 \mathrm{nmol} / \mathrm{L}$ in summer $(n=14)$, and $65.8 \pm 3.7 \mathrm{nmol} / \mathrm{L}$ in fall $(n=32)$. Figure 3 depicts the relative change over the neoadjuvant course for individuals who had baseline and either post$\mathrm{Rx}$ or evaluation measures, as categorized by season of diagnosis. For the actual cases $(n=63$ and $n=60$, respectively), median time from baseline to post-Rx serum sampling was 68 (range, 62-90) days and 98 (range, 89-126) days to evaluation sampling. Again, significant seasonal differences were observed within both datasets ( $p=$ 0.00072 and $p=0.00013$, respectively). Specifically, $25(\mathrm{OH}) \mathrm{D}$ fold-change (mean $\pm \mathrm{SE}$ ) from baseline to post$\mathrm{Rx}$ or to evaluation was $-0.11 \pm 0.09$ and $0.05 \pm 0.06$ in the winter category, $0.17 \pm 0.06$ and $0.34 \pm 0.09$ in the spring category, $-0.14 \pm 0.07$ and $-0.12 \pm 0.08$ in the summer category, and $-0.11 \pm 0.04$ and $-0.10 \pm 0.03$ in the fall category. Hence, a majority of patients diagnosed in winter and spring experienced elevation in serum 25(OH)D over the neoadjuvant period; correspondingly, a decline occurred in most patients diagnosed in summer and fall. After season adjustment for each case by the linear-mixed model, however, only minor alterations in serum $25(\mathrm{OH})$ $\mathrm{D}$ were observed from baseline to post-Rx (mean increase of 0.58 units for the entire cohort; $p=0.24$ ) and evaluation (mean decrease of 2.1 units for the entire cohort; $p=0.75$ ), indicating that the neoadjuvant treatment as such may not have affected circulating 25(OH)D. The baseline 25(OH)D measure for each patient was therefore used in all of the subsequent analyses.

\section{Serum 25(OH)D level and disease presentation}

As shown in Table 1, 25(OH)D was not correlated with age, sex, or BMI. Low 25(OH)D was significantly correlated with reduced performance status (ECOG 1; $p=$ $0.031)$ and anemia $(p=0.004)$. Interestingly, the mean $25(\mathrm{OH}) \mathrm{D}$ measures in patients with these unfavorable clinical features were just below the lower reference interval limit for maintenance of a normal bone metabolism (50 nmol/L) [12]. Moreover, the patient group with T4 disease had significantly lower 25(OH)D $(52.5 \pm 3.9$ $\mathrm{nmol} / \mathrm{L})$ than T2-3 cases $(63.0 \pm 3.1 \mathrm{nmol} / \mathrm{L} ; p=0.040)$ and similarly, there was an inverse correlation between $25(\mathrm{OH}) \mathrm{D}$ value and tumor volume $(r=-0.267 ; p=$ 0.025). All of these associations were maintained after season adjustment, with ECOG status as the statistically strongest factor $(p=0.015)$. Furthermore, a separate analysis showed no association between season alone and any of these features (not shown). Ten patients with T4 disease (32.3\%) had particularly low 25(OH)D (below 35 nmol/L; Fig. 2). As listed in Table 2, no correlations were seen between serum $25(\mathrm{OH}) \mathrm{D}$ and circulating levels of calcium, albumin (the main calcium-binding protein), or carcinoembryonic antigen (a CRC tumor marker). Analyses indicated inverse correlations between the $25(\mathrm{OH})$ $\mathrm{D}$ and common markers of systemic inflammation $(\mathrm{C}$ reactive protein, erythrocyte sedimentation rate, and neutrophil-to-lymphocyte ratio), but statistical significance did not persist after correction for multiple comparisons.

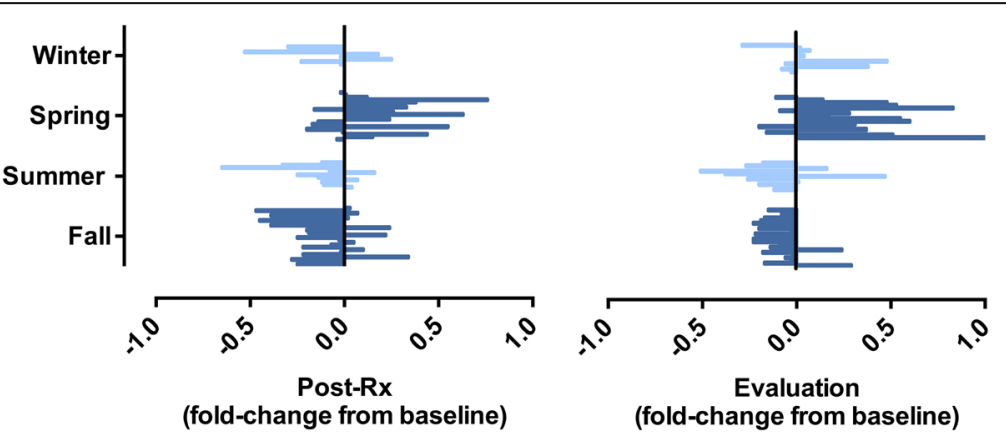

Fig. 3 The relative change of serum 25-hydroxyvitamin D level over the neoadjuvant course for individual study subjects. Each patient is represented by a line and assigned a group according to the season of diagnosis. Abbreviation: Post-Rx completion of neoadjuvant therapy 
Table 1 Serum content of vitamin D and correlations with patient and disease factors

\begin{tabular}{|c|c|c|c|c|c|c|}
\hline & & $n(\%)$ & 25(OH)D $($ mean $\pm \mathrm{SE}), \mathrm{nmol} / \mathrm{L}$ & $r$ & $p^{a}$ & $p^{\mathrm{b}}$ \\
\hline Median age (range), years & $58.5(30-73)$ & $84(100)$ & & 0.079 & 0.48 & 0.45 \\
\hline \multirow[t]{2}{*}{ Sex } & Female & $34(40.5)$ & $60.2 \pm 4.2$ & & & \\
\hline & Male & $50(59.5)$ & $58.4 \pm 3.1$ & & 0.72 & 0.76 \\
\hline BMI (mean $\pm S D), \mathrm{kg} / \mathrm{m}^{2}$ & $24.1 \pm 3.5$ & $83(98.8)$ & & -0.046 & 0.68 & 0.60 \\
\hline \multirow[t]{2}{*}{ ECOG } & 0 & $67(79.8)$ & $61.8 \pm 2.7$ & & & \\
\hline & 1 & $17(20.2)$ & $48.5 \pm 5.6$ & & 0.031 & 0.015 \\
\hline \multirow[t]{2}{*}{ Hemoglobin } & Normal & $63(75.0)$ & $63.2 \pm 2.7$ & & & \\
\hline & Anemic $^{c}$ & $21(25.0)$ & $47.0 \pm 5.1$ & & 0.004 & 0.029 \\
\hline Median tumor volume (range), $\mathrm{cm}^{3}$ & $16.7(1.0-293)^{d}$ & $71(84.5)$ & & -0.267 & 0.025 & 0.024 \\
\hline \multirow[t]{2}{*}{ T stage } & $2-3$ & $53(63.1)$ & $63.0 \pm 3.1$ & & & \\
\hline & 4 & $31(36.9)$ & $52.5 \pm 3.9$ & & 0.040 & 0.028 \\
\hline \multirow[t]{2}{*}{ N stage } & 0 & $11(13.1)$ & $62.1 \pm 7.7$ & & & \\
\hline & $1-2$ & $73(86.9)$ & $58.7 \pm 2.6$ & & 0.65 & 0.95 \\
\hline \multirow[t]{2}{*}{ ypT stage ${ }^{e}$} & $0-3$ & $66(78.5)$ & $62.4 \pm 2.7$ & & & \\
\hline & 4 & $17(20.2)$ & $48.1 \pm 5.6$ & & 0.019 & 0.018 \\
\hline \multirow[t]{2}{*}{ ypN stage $e^{e}$} & 0 & $56(66.7)$ & $61.2 \pm 3.3$ & & & \\
\hline & $1-2$ & $27(32.1)$ & $55.9 \pm 3.5$ & & 0.33 & 0.21 \\
\hline
\end{tabular}

Abbreviations: $25(\mathrm{OH}) \mathrm{D}$ 25-hydroxyvitamin D, BMI body mass index, ECOG Eastern Cooperative Oncology Group performance status, SD standard deviation, SE standard error, $T N$ tumor-node, $y p$ histologic response to neoadjuvant therapy

${ }^{a}$ Described by Pearson correlation test or independent sample $t$-test

${ }^{b}$ Estimated by linear and logistic regression models, with winter/spring and summer/fall as collapsed categories

${ }^{c}$ Anemia was defined as hemoglobin level below the lower reference interval limit used in Norway $(<11.7 \mathrm{~g} / \mathrm{dL}$ for women and $<13.4 \mathrm{~g} / \mathrm{dL}$ for men)

${ }^{\mathrm{d}}$ The data were log-transformed before analysis

${ }^{e}$ One patient died unexpectedly before pelvic surgery; as a consequence, histologic tumor response data was missing, and the single case was omitted from these analyses

Table 2 Serum content of vitamin D and correlations with other circulating factors ${ }^{\mathrm{a}}$

\begin{tabular}{llll}
\hline & $n(\%)$ & $r$ & $p^{\mathrm{b}}$ \\
\hline CEA & $84(100)$ & 0.071 & 0.52 \\
Calcium & $82(97.6)$ & 0.202 & 0.069 \\
Albumin & $84(100)$ & 0.176 & 0.11 \\
CRP & $70(83.3)$ & -0.285 & $0.017^{c}$ \\
ESR & $75(89.3)$ & -0.315 & $0.006^{c}$ \\
Leukocytes & $84(100)$ & -0.163 & 0.14 \\
Neutrophils & $84(100)$ & -0.207 & 0.059 \\
Lymphocytes & $82(97.6)$ & 0.109 & 0.33 \\
NLR & $82(97.6)$ & -0.237 & $0.032^{c}$ \\
Monocytes & $81(96.4)$ & 0.025 & 0.83 \\
Thrombocytes & $84(100)$ & -0.043 & 0.70 \\
LDH & $84(100)$ & 0.150 & 0.17 \\
Creatinine & $84(100)$ & 0.180 & 0.10 \\
\hline
\end{tabular}

Abbreviations: CEA carcinoembryonic antigen, CRP C-reactive protein, ESR erythrocyte sedimentation rate, $L D H$ lactate dehydrogenase, $N L R$

neutrophil-to-lymphocyte ratio

${ }^{a}$ All measures of circulating factors but 25 -hydroxyvitamin D were logtransformed before analysis

${ }^{b}$ Estimated by Pearson correlation test

'Significant $p$-value did not persist after correction for multiple comparisons of

12 datasets on circulating markers possibly related to tumor immune

responses, which excluded that on CEA

\section{Serum 25(OH)D level and treatment effects}

As further shown in Table 1, patients who obtained poor tumor response to the neoadjuvant treatment (ypT4) had lower baseline $25(\mathrm{OH}) \mathrm{D}(48.1 \pm 5.6 \mathrm{nmol} / \mathrm{L})$ than ypT0-3 cases $(62.4 \pm 2.7 \mathrm{nmol} / \mathrm{L} ; p=0.019$, maintained after season adjustment). In practice, only $\mathrm{T} 4$ cases may obtain a ypT4 outcome. Hence, the data indicated that the neoadjuvant treatment in patients with $\mathrm{T} 4$ disease and $25(\mathrm{OH}) \mathrm{D}$ measures below the defined sufficiency for normal bone metabolism [12] resulted in ypT4 (i.e., lack of response), in contrast to $\mathrm{T} 4$ patients achieving ypT03 (i.e., response) who presented $25(\mathrm{OH}) \mathrm{D}$ identical to T2 -3 cases. In other words, T4 patients $(n=30$, as one patient unexpectedly died before pelvic surgery) apparently consisted of two groups of subjects in regard to circulating $25(\mathrm{OH}) \mathrm{D}-\mathrm{one}(n=13)$ that was biologically similar to T2-3 cases and the other $(n=17)$ with therapy-resistant disease. In contrast to ypT stage, no correlation was found between $25(\mathrm{OH}) \mathrm{D}$ and residual lymph nodes in the surgical specimen.

As shown in Table 3, when censored, 31 individuals (36.9\% of the study population) had experienced a PFS event. Median time to an event was 13.3 (range, 1.240.1) months. Four patients had local recurrence as the first event and 27 patients had distant organ disease. 
Table 3 Serum content of vitamin D and correlations with survival endpoints

\begin{tabular}{|c|c|c|c|c|c|c|}
\hline & T2-3 cases & & & T4 cases & & \\
\hline $25(\mathrm{OH}) \mathrm{D}, \mathrm{nmol} / \mathrm{L}$ & $<50$ & $\geq 50$ & $p^{\mathrm{a}}$ & $<50$ & $\geq 50$ & $p^{\mathrm{a}}$ \\
\hline \multicolumn{7}{|l|}{ PFS } \\
\hline No. at risk & 18 & 35 & & 14 & 17 & \\
\hline No. of events & 4 & 12 & & 9 & 6 & \\
\hline \multirow[t]{2}{*}{ Univariable HR (95\% Cl) } & 0.626 & Referent & 0.42 & 2.53 & Referent & 0.080 \\
\hline & $(0.202-1.94)$ & & & $(0.895-7.12)$ & & \\
\hline \multirow[t]{2}{*}{ Multivariable HR $(95 \% \mathrm{Cl})^{\mathrm{b}}$} & 0.720 & Referent & 0.59 & 3.09 & Referent & 0.048 \\
\hline & $(0.220-2.38)$ & & & $(1.01-9.45)$ & & \\
\hline \multicolumn{7}{|l|}{ OS } \\
\hline No. at risk & 18 & 35 & & 14 & 17 & \\
\hline No. of events & 2 & 5 & & 7 & 1 & \\
\hline \multirow[t]{2}{*}{ Univariable HR (95\% Cl) } & 0.714 & Referent & 0.69 & 10.8 & Referent & 0.026 \\
\hline & $(0.180-3.69)$ & & & $(1.33-88.3)$ & & \\
\hline \multirow[t]{2}{*}{ Multivariable HR $(95 \% \mathrm{Cl})^{\mathrm{b}}$} & 0.783 & Referent & 0.79 & 17.6 & Referent & 0.010 \\
\hline & $(0.130-4.84)$ & & & $(1.99-155)$ & & \\
\hline
\end{tabular}

Abbreviations: $25(\mathrm{OH}) \mathrm{D}$ 25-hydroxyvitamin $\mathrm{D}, \mathrm{Cl}$ confidence interval, $H R$ hazard ratio, OS overall survival, $P F S$ progression-free survival, $T$ tumor stage ${ }^{a}$ Estimated by Cox proportional hazards models

${ }^{\mathrm{b}}$ Adjusted for age, sex, body mass index, and season (winter/spring and summer/fall as collapsed categories)

Furthermore, 15 deaths (17.9\% of the population) were recorded, with median time to death of 32.8 (range, 1.268.3) months and median follow-up time for participants still alive of 74.5 (range, 41.2-94.0) months. Motivated by the findings pertaining to serum $25(\mathrm{OH}) \mathrm{D}$ and $\mathrm{T}$ and ypT stages, subjects with T2-3 and T4 disease were separately stratified according to baseline $25(\mathrm{OH}) \mathrm{D}$ above or below $50 \mathrm{nmol} / \mathrm{L}$ for survival analyses. By this, no significant association was found between $25(\mathrm{OH}) \mathrm{D}$ and either PFS or OS in T2-3 cases; however, a higher PFS percentage was observed for the vitamin D-high cases. For patients with T4 disease and sufficient $25(\mathrm{OH}) \mathrm{D}$, the percentage of recorded PFS events (six of 17 cases; 35.3\%) was equal to that of the corresponding T2-3 group (12 of 35 cases; 34.3\%). In contrast, T4 patient with insufficient $25(\mathrm{OH}) \mathrm{D}$ had almost twice as many PFS events (nine of 14 cases; 64.3\%), which translated into a heightened risk compared to T4 patients with sufficient vitamin D status (HR 3.09, 95\% CI 1.01-9.45; $p=$ 0.048 when adjusted for age, sex, BMI, and season). Similarly, the vitamin D-low cases in the T4 group had considerably enhanced risk of death (HR 17.6, 95\% CI $1.99-155 ; p=0.010$ in the adjusted model).

\section{Discussion}

In LARC patients residing at latitude $58-62^{\circ} \mathrm{N}$, circulating $25(\mathrm{OH}) \mathrm{D}$ levels reflected the season of diagnosis, displaying a mean group measure $50 \%$ higher in summer compared to spring, and changed during the well over 3-month period till treatment evaluation essentially owing to season alone. As group, patients who presented organ-invasive tumor showed a mean serum concentration above $50 \mathrm{nmol} / \mathrm{L}$, but a third of T4 cases had strikingly low $25(\mathrm{OH}) \mathrm{D}$ (below $35 \mathrm{nmol} / \mathrm{L}$ ). Individuals who presented T4 disease that did not respond to the neoadjuvant treatment (ypT4 cases) and systemic manifestations in terms of reduced performance status and anemia, translating into unfavorable survival outcome, had a group mean level just below $50 \mathrm{nmol} / \mathrm{L}$. This was notably different from $\mathrm{T} 4$ cases with response (yp $\mathrm{T} 0-3$ ), who presented levels identical to T2-3 cases (mean above $60 \mathrm{nmol} / \mathrm{L}$ ). Our results indicate that serum content of $25(\mathrm{OH}) \mathrm{D}$ below the lower limit of the reference interval $(50 \mathrm{nmol} / \mathrm{L})$ impacts unfavorably, or simply reflects unfavorable rectal cancer biology and treatment outcome.

Due to the spectrum and intensity variation of ultraviolet $\mathrm{B}$ in solar radiation reaching the Nordic countries, inhabitants present an annual fluctuation of circulating $25(\mathrm{OH}) \mathrm{D}$ with roughly $50 \%$ higher serum concentrations in late summer and early fall compared to winter and spring $[9,27]$. This has also been reported for CRC patients $[9,10]$ and was found again in the present cohort. Following adjustment for change in season, study patients' individual $25(\mathrm{OH}) \mathrm{D}$ levels over the time from diagnosis to treatment evaluation did not seem to be affected otherwise. The observed variations in circulating $25(\mathrm{OH}) \mathrm{D}$ owing to season only are in accordance with a study on Norwegian patients with multiple sclerosis, where the predicted time-adjusted value of serum 25(OH)D for the individual patient was relatively stable [28]. 
Antitumor effects of the active vitamin D metabolite, calcitriol, or synthetic analogs have been extensively examined in experimental models [29-31] and for CRC, such effects have been shown to implicate cell proliferation and differentiation, apoptosis, and immune modulation [32-34]. Hence, our findings of inverse correlations between the 25(OH)D level and tumor stage and volume may essentially reflect biological effects. However, it is not possible from our data to determine whether the poorer patient performance status and anemia were results of low 25(OH)D level per se, or if these patient features were instead concurrent but mutually independent manifestations of the high-risk disease in this particular subgroup of T4 cases. The absence of a clear correlation between circulating $25(\mathrm{OH}) \mathrm{D}$ and systemic inflammation markers may serve as an argument against the former. In this regard, interventional studies may provide causal evidence.

Our findings that patients with $\mathrm{T} 2-3$ or $\mathrm{T} 4$ disease who obtained the intended treatment surrogate responses had 25(OH)D levels well above the lower limit of the reference interval, suggest that the $25(\mathrm{OH}) \mathrm{D}$ concentration must be of a certain magnitude to possibly act synergistically with cytotoxic agents. Preclinical studies have demonstrated that vitamin D analogs enhance the effect of chemotherapy and radiation in breast and non-small cell lung carcinomas through mechanistic interactions [35-37]. In a retrospective review of high-risk breast cancer patients receiving neoadjuvant chemotherapy, subjects with vitamin D supplementation had significantly longer disease-free survival than those without [38]. The recently reported prospective SUNSHINE study in patients with metastatic CRC on first-line systemic therapy revealed that those randomized to highdose vitamin D supplementation experienced longer PFS than the control group patients given a standard vitamin $\mathrm{D}$ dose [39]. Finally, observational studies and metaanalyses have shown that high circulating vitamin $\mathrm{D}$ concentrations may lower CRC risk [40, 41] and improve prognosis $[4,42-46]$. Within this frame of reference, the most noteworthy observation in our study is that a considerable number of patients with organ-invasive disease within the pelvic cavity, which is regarded as the 'ugly' rectal cancer entity [17], obtained tumor down-staging and surprisingly good clinical outcome-when presenting with circulating $25(\mathrm{OH}) \mathrm{D}$ levels like individuals with T2-3 disease. Regarding the lack of correlation between $25(\mathrm{OH}) \mathrm{D}$ and residual lymph nodes in the surgical specimen, it might be that a favorable stromal reprogramming of the tumor microenvironment by vitamin $\mathrm{D}$, as has been demonstrated in experimental pancreatic cancer models [47], does not occur in lymphatic tissues.

There are evident limitations of this post hoc study. First, the cohort is small and results must be interpreted cautiously. On the other hand, more than a third of patients had T4 disease, which firstly is uncommon in reported LARC studies and secondly represented a balanced vitamin D-low versus vitamin D-high population. Next, the analyses reported here had not been planned at the time of trial conduct. Consequently, the observed associations between circulating $25(\mathrm{OH}) \mathrm{D}$ and disease presentation and outcome are likely confounded by diet and lifestyle factors, which were not recorded. For instance, occasional sun exposure due to traveling to sunny destinations in darker months is common among citizens of Norway, possibly resulting in less seasonal variation than could be expected for persons living at the actual latitudes. Nevertheless, adjustment for season confounding of the repeat serum 25(OH)D measures over the neoadjuvant period revealed that each individual patient's level was remarkably stable. Finally, the study did not have a separate validation cohort, which might be difficult to identify because of the geographic relevance.

\section{Conclusions}

The data in this report indicate that curative-intent neoadjuvant therapy in LARC is less likely to succeed if circulating $25(\mathrm{OH}) \mathrm{D}$ is below $50 \mathrm{nmol} / \mathrm{L}$, independent of season, in cases with organ-invasive disease at presentation. Hence, a prospective study with vitamin D supplementation during neoadjuvant therapy may provide evidence for causal effects, if existing.

\section{Abbreviations}

25(OH) $\mathrm{D}_{3}$ : 25-Hydroxyvitamin $\mathrm{D}_{3}$; BMI: Body Mass Index; Cl: Confidence Interval; CRC: Colorectal Cancer; ECOG: Eastern Cooperative Oncology Group; HR: Hazard Ratio; LARC: Locally Advanced Rectal Cancer; OS: Overall Survival; PFS: Progression-Free Survival; Post-Rx: Completion of Neoadjuvant Therapy; SD: Standard Deviation; SE: Standard Error; TN: Tumor-Node; yp: Histologic Response to Neoadjuvant Therapy

\section{Acknowledgments}

The authors are indebted to the late Professor Lage Aksnes, Haukeland University Hospital (Bergen, Norway) for his contribution to this study.

\section{Funding}

This work was supported by the South-Eastern Norway Regional Health Authority (grants 2015033 and 2017109 to AHR and grants 2013002 and 2016050 to KRR). The funding source had no role in the study design, collection, analysis, and interpretation of data, or writing of the report.

Availability of data and materials

The datasets used and analyzed during the current study are available from the corresponding author on reasonable request.

\section{Authors' contributions}

AHR, ACP, and JM developed the study concept and design. AHR, SD, KF, $\mathrm{KHH}, \mathrm{TS}$, and KRR managed the provision of study material and patients. HA, $A C P, J C L$, and SM collected and assembled the data. HA and AHR drafted the manuscript, and all authors read and approved the final version.

\section{Ethics approval and consent to participate}

The study protocol was approved by the Institutional Review Board and the Regional Committee for Medical and Health Research Ethics (REK-S-05059). The study was performed in accordance with the Declaration of Helsinki. Written informed consent was required for participation. 


\section{Consent for publication}

Not applicable.

\section{Competing interests}

The authors declare that they have no competing interests.

\section{Publisher's Note}

Springer Nature remains neutral with regard to jurisdictional claims in published maps and institutional affiliations.

\section{Author details}

'Department of Oncology, Akershus University Hospital, P.O. Box 1000, 1478 Lørenskog, Norway. ${ }^{2}$ Institute of Clinical Medicine, University of Oslo, Oslo, Norway. ${ }^{3}$ Department of Oncology, Vestre Viken Hospital Trust, Drammen, Norway. ${ }^{4}$ Health Services Research Center, Akershus University Hospital, Lørenskog, Norway. ${ }^{5}$ Department of Oncology, Oslo University Hospital, Oslo, Norway. ${ }^{6}$ Department of Gastroenterological Surgery, Oslo University Hospital, Oslo, Norway. ${ }^{7}$ Department of Tumor Biology, Oslo University Hospital, Oslo, Norway. ${ }^{8}$ Department of Radiology, Oslo University Hospital, Oslo, Norway. ${ }^{9}$ Department of Radiation Oncology, Oslo University Hospital, Oslo, Norway. ${ }^{10}$ Institute of Physics, University of Oslo, Oslo, Norway. ${ }^{11}$ Department of Physics, Norwegian University of Science and Technology, Trondheim, Norway.

Received: 11 May 2018 Accepted: 16 May 2019

Published online: 23 May 2019

\section{References}

1. Arnold M, Karim-Kos HE, Coebergh JW, Byrnes G, Antilla A, Ferlay J, et al. Recent trends in incidence of five common cancers in 26 European countries since 1988: analysis of the European Cancer observatory. Eur J Cancer. 2015;51:1164-87.

2. Garland CF, Garland FC. Do sunlight and vitamin D reduce the likelihood of colon cancer? Int J Epidemiol. 1980;9:227-31.

3. Ma Y, Zhang P, Wang F, Yang J, Liu Z, Qin H. Association between vitamin $D$ and risk of colorectal cancer: a systematic review of prospective studies. J Clin Oncol. 2011;29:3775-82.

4. Mohr SB, Gorham ED, Kim J, Hofflich H, Cuomo RE, Garland CF. Could vitamin D sufficiency improve the survival of colorectal cancer patients? J Steroid Biochem Mol Biol. 2015;148:239-44.

5. Armas LA, Dowell S, Akhter M, Duthuluru S, Huerter C, Hollis BW, et al. Ultraviolet-B radiation increases serum 25-hydroxyvitamin D levels: the effect of UVB dose and skin color. J Am Acad Dermatol. 2007;57:588-93.

6. Engelsen $O$, Brustad M, Aksnes L, Lund E. Daily duration of vitamin D synthesis in human skin with relation to latitude, total ozone, altitude, ground cover, aerosols and cloud thickness. Photochem Photobiol. 2005;81: 1287-90.

7. Grigalavicius M, Moan J, Dahlback A, Juzeniene A. Daily, seasonal, and latitudinal variations in solar ultraviolet $A$ and $B$ radiation in relation to vitamin D production and risk for skin cancer. Int J Dermatol. 2016;55:e23-8.

8. Moan J, Dahlback A, Lagunova Z, Cicarma E, Porojnicu AC. Solar radiation, vitamin D and cancer incidence and mortality in Norway. Anticancer Res. 2009;29:3501-9.

9. Moan J, Porojnicu AC, Robsahm TE, Dahlback A, Juzeniene A, Tretli S, et al. Solar radiation, vitamin $D$ and survival rate of colon cancer in Norway. J Photochem Photobiol B. 2005;78:189-93.

10. Moan J, Porojnicu A, Lagunova Z, Berg JP, Dahlback A. Colon cancer: prognosis for different latitudes, age groups and seasons in Norway. $J$ Photochem Photobiol B. 2007;89:148-55.

11. Nemazannikova N, Antonas K, Dass CR. Vitamin D: metabolism, molecular mechanisms, and mutations to malignancies. Mol Carcinog. 2014;53:421-31.

12. Lamberg-Allardt C, Brustad M, Meyer HE, Steingrimsdottir L. Vitamin D - a systematic literature review for the 5 th edition of the Nordic nutrition recommendations. Food Nutr Res. 2013;57.

13. Bischoff-Ferrari HA. Optimal serum 25-hydroxyvitamin D levels for multiple health outcomes. Adv Exp Med Biol. 2008;624:55-71.

14. van Schoor NM, Lips P. Worldwide vitamin D status. Best Pract Res Clin Endocrinol Metab. 2011;25:671-80.

15. Goldsmith JR. Vitamin D as an immunomodulator: risks with deficiencies and benefits of supplementation. Healthcare (Basel). 2015;3:219-32.
16. Ananthakrishnan AN, Cheng SC, Cai T, Cagan A, Gainer VS, Szolovits P, et al. Association between reduced plasma 25-hydroxy vitamin D and increased risk of cancer in patients with inflammatory bowel diseases. Clin Gastroenterol Hepatol. 2014;12:821-7.

17. Blomqvist L, Glimelius B. The 'good', the 'bad', and the 'ugly' rectal cancers. Acta Oncol. 2008:47:5-8.

18. Dueland S, Ree AH, Grøholt KK, Saelen MG, Folkvord S, Hole KH, et al. Oxaliplatin-containing preoperative therapy in locally advanced rectal cancer: local response, toxicity and long-term outcome. Clin Oncol (R Coll Radiol). 2016;28:532-9.

19. Holick MF. Vitamin D status: measurement, interpretation, and clinical application. Ann Epidemiol. 2009;19:73-8.

20. Agborsangaya C, Toriola AT, Grankvist K, Surcel HM, Holl K, Parkkila S, et al The effects of storage time and sampling season on the stability of serum 25-hydroxy vitamin D and androstenedione. Nutr Cancer. 2010;62:51-7.

21. Ockè MC, Schrijver J, Obermann-de Boer GL, Bloemberg BP, Haenen GR, Kromhout D. Stability of blood (pro)vitamins during four years of storage at -20 degrees C: consequences for epidemiologic research. J Clin Epidemiol. 1995:48:1077-85.

22. Aksnes L. Simultaneous determination of retinol, alpha-tocopherol, and 25hydroxyvitamin D in human serum by high-performance liquid chromatography. J Pediatr Gastroenterol Nutr. 1994;18:339-43.

23. Seierstad T, Hole KH, Grøholt KK, Dueland S, Ree AH, Flatmark K, et al. MRI volumetry for prediction of tumour response to neoadjuvant chemotherapy followed by chemoradiotherapy in locally advanced rectal cancer. $\mathrm{Br} J$ Radiol. 2015;88:20150097.

24. Flatmark K, Saelen MG, Hole KH, Abrahamsen TW, Fleten KG, Hektoen HH, et al. Individual tumor volume responses to short-course oxaliplatin-containing induction chemotherapy in locally advanced rectal cancer - targeting the tumor for radiation sensitivity? Radiother Oncol. 2016;119:505-11.

25. The MERCURY study group. Diagnostic accuracy of preoperative magnetic resonance imaging in predicting curative resection of rectal cancer: prospective observational study. BMJ. 2006;333:779.

26. Bates $D$, Mächler $M$, Bolker $B$, et al. Fitting linear mixed-effects models using Ime4. J Stat Softw. 2015;67:1-48.

27. Moosgaard B, Vestergaard $P$, Heickendorff $L$, Melsen F, Christiansen $P$, Mosekilde L. Vitamin D status, seasonal variations, parathyroid adenoma weight and bone mineral density in primary hyperparathyroidism. Clin Endocrinol. 2005;63:506-13.

28. Saltyte Benth J, Myhr KM, Løken-Amsrud Kl, Beiske AG, Bjerve KS, Hovdal H, et al. Modelling and prediction of 25-hydroxyvitamin D levels in Norwegian relapsing-remitting multiple sclerosis patients. Neuroepidemiology. 2012;39: 84-93.

29. Chiang KC, Chen TC. The anti-cancer actions of vitamin D. Anti Cancer Agents Med Chem. 2013;13:126-39.

30. Dou R, Ng K, Giovannucci EL, Manson JE, Qian ZR, Ogino S. Vitamin D and colorectal cancer: molecular, epidemiological and clinical evidence. $\mathrm{Br}$ J Nutr. 2016;115:1643-60.

31. Christakos S, Dhawan P, Verstuyf A, Verlinden L, Carmeliet G. Vitamin D: metabolism, molecular mechanism of action, and pleiotropic effects. Physiol Rev. 2016;96:365-408.

32. Evans SR, Schwartz AM, Shchepotin El, Uskokovic M, Shchepotin IB. Growth inhibitory effects of 1,25-dihydroxyvitamin D3 and its synthetic analogue, 1alpha,25-dihydroxy-16-ene-23yne-26,27-hexafluoro-19-nor-cholecalciferol (Ro 25-6760), on a human colon cancer xenograft. Clin Cancer Res. 1998:4:2869-76.

33. Huerta S, Irwin RW, Heber D, Go VL, Koeffler HP, Uskokovic MR, et al. lalpha,25-(OH)(2)-D (3) and its synthetic analogue decrease tumor load in the Apc(min) Mouse. Cancer Res. 2002;62:741-6.

34. Zheng W, Wong KE, Zhang Z, Dougherty U, Mustafi R, Kong J, et al. Inactivation of the vitamin D receptor in $\mathrm{APC}(\mathrm{min} /+)$ mice reveals a critical role for the vitamin D receptor in intestinal tumor growth. Int J Cancer. 2012;130:10-9.

35. Wang Q, Yang W, Uytingco MS, Christakos S, Wieder R. 1,25Dihydroxyvitamin D3 and all-trans-retinoic acid sensitize breast cancer cells to chemotherapy-induced cell death. Cancer Res. 2000;60:2040-8.

36. Chaudhry M, Sundaram S, Gennings C, Carter H, Gerwirtz DA. The vitamin D3 analog, ILX-23-7553, enhances the response to adriamycin and irradiation in MCF-7 breast tumor cells. Cancer Chemother Pharmacol. 2001;47:429-36.

37. Sharma K, Goehe RW, Di X, Hicks MA 2nd, Torti SV, Harada H, et al. A novel cytostatic form of autophagy in sensitization of non-small cell lung cancer cells to radiation by vitamin D and the vitamin D analog, EB 1089. Autophagy. 2014;10:2346-61. 
38. Zeichner SB, Koru-Sengul T, Shah N, Liu Q, Markward NJ, Montero AJ, et al. Improved clinical outcomes associated with vitamin D supplementation during adjuvant chemotherapy in patients with HER2+ nonmetastatic breast cancer. Clin Breast Cancer. 2015;15:e1-11.

39. Ng K, Nimeiri HS, MCCleary NJ, Abrams TA, Yurgelun MB, Cleary JM, et al. Effects of high-dose vs standard-dose vitamin $\mathrm{D}_{3}$ supplementation on progression-free survival among patients with advanced or metastatic colorectal cancer: the SUNSHINE randomized clinical trial. JAMA. 2019;321: 1370-9.

40. Song M, Konijeti GG, Yuan C, Ananthakrishnan AN, Ogino S, Fuchs CS, et al. Plasma 25-hydroxyvitamin D, vitamin D binding protein, and risk of colorectal cancer in the Nurses' Health Study. Cancer Prev Res (Phila). 2016; 9:664-72.

41. Song M, Nishihara R, Wang M, Chan AT, Qian ZR, Inamura K, et al. Plasma 25-hydroxyvitamin $D$ and colorectal cancer risk according to tumour immunity status. Gut. 2016;65:296-304.

42. Ng K, Meyerhardt JA, Wu K, Feskanich D, Hollis BW, Giovannucci EL, et al. Circulating 25-hydroxyvitamin d levels and survival in patients with colorectal cancer. J Clin Oncol. 2008;26:2984-91.

43. Ng K, Sargent DJ, Goldberg RM, Meyerhardt JA, Green EM, Pitot HC, et al. Vitamin D status in patients with stage IV colorectal cancer: findings from Intergroup trial N9741. J Clin Oncol. 2011;29:1599-606.

44. Ng K. Vitamin D for prevention and treatment of colorectal cancer: what is the evidence? Curr Colorectal Cancer Rep. 2014;10:339-45.

45. Maalmi H, Ordonez-Mena JM, Schöttker B, Brenner H. Serum 25hydroxyvitamin D levels and survival in colorectal and breast cancer patients: systematic review and meta-analysis of prospective cohort studies. Eur J Cancer. 2014;50:1510-21.

46. Wang B, Jing Z, Li C, Xu S, Wang Y. Blood 25-hydroxyvitamin D levels and overall mortality in patients with colorectal cancer: a dose-response metaanalysis. Eur J Cancer. 2014;50:2173-5.

47. Sherman MH, Yu RT, Engle DD, Ding N, Atkins AR, Tiriac H, et al. Vitamin D receptor-mediated stromal reprogramming suppresses pancreatitis and enhances pancreatic cancer therapy. Cell. 2014;159:80-93.

Ready to submit your research? Choose BMC and benefit from:

- fast, convenient online submission

- thorough peer review by experienced researchers in your field

- rapid publication on acceptance

- support for research data, including large and complex data types

- gold Open Access which fosters wider collaboration and increased citations

- maximum visibility for your research: over $100 \mathrm{M}$ website views per year

At $\mathrm{BMC}$, research is always in progress.

Learn more biomedcentral.com/submissions 